\title{
Correction to: Machine learning techniques for pathogenicity prediction of non-synonymous single nucleotide polymorphisms in human body
}

\author{
Enas M. F. El Houby ${ }^{1}$ (D)
}

๑) Springer-Verlag GmbH Germany, part of Springer Nature 2022

\section{Correction to: \\ Journal of Ambient Intelligence and Humanized \\ Computing \\ https://doi.org/10.1007/s12652-021-03581-3}

In the original article the below Pseudocode 1 has been missed to be added and was unfortunately processed as ESM.

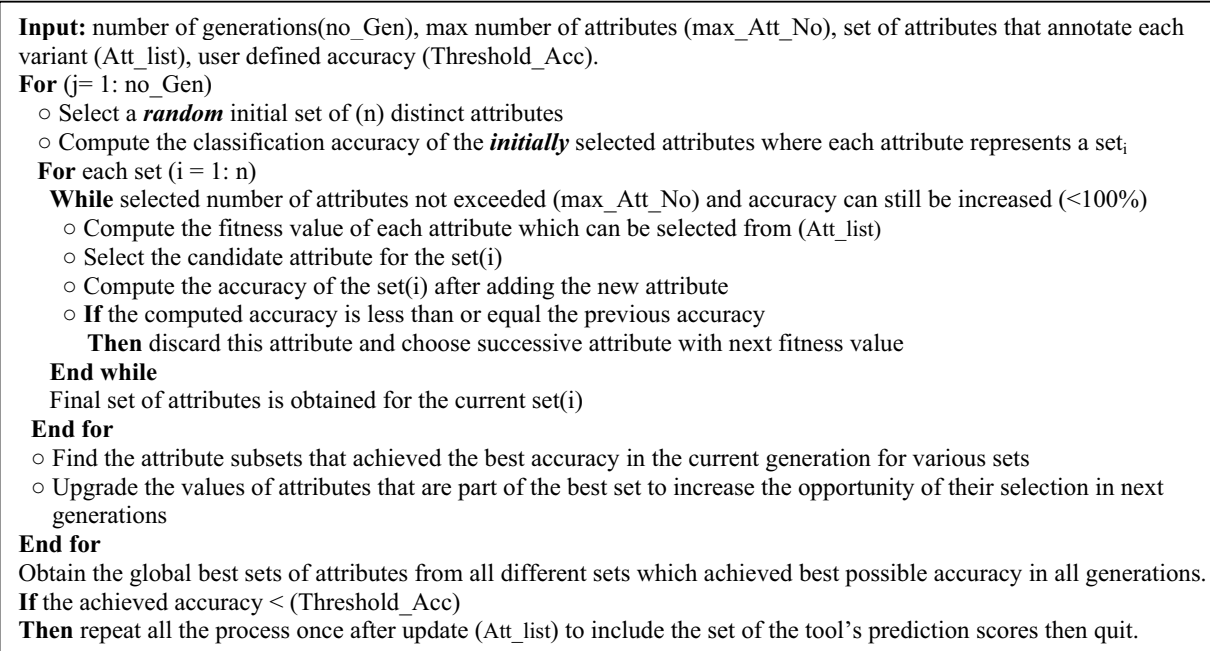

The original article can be found online at https://doi.org/10.1007/ s12652-021-03581-3.

Enas M. F. El Houby

enas_mfahmy@yahoo.com; em.fahmy@nrc.sci.eg

Publisher's Note Springer Nature remains neutral with regard to jurisdictional claims in published maps and institutional affiliations.

1 Systems \& Information Department, Engineering Research Division, National Research Centre (NRC), Dokki,

Cairo 12622, Egypt 